Año 11.

Revista de Investigación

Núm. 28

Académica sin Frontera

ISSN: 2007-8870

\title{
http://revistainvestigacionacademicasinfrontera.com
}

Recibido el 24 de junio de 2018.

Dictaminado mediante arbitraje favorablemente 3 de noviembre de 2018

\section{Estructura categorial y subcategorial en la exploración de notas de prensa relativas a la administración de la seguridad migratoria}

Categorical structure and subcategories in the exploration of press releases related to the administration of migratory security

Arturo Sánchez-Sánchez ${ }^{1}$, Fermín Anguiano-Salazar ${ }^{2}$, Héctor Daniel Molina-Ruíz ${ }^{3}$, Lidia Amalia Zallas Esquer ${ }^{4}$, Wilfrido Isidro Aldana-Balderas ${ }^{5}$, Gabriel Pérez-Crisanto ${ }^{6}$, Abigail Quezada-Castro $^{7}$, Cruz García-Lirios ${ }^{8}$

Resumen -El objetivo del presente estudio es establecer un ciclo sociopsicológico de la inseguridad relativa a la migración y su correspondiente índice para medir el grado de mediatización de la prensa en torno a las notas periodísticas sobre la problemática. Para tal propósito, se utilizó la teoría de los ciclos y la Teoría del Establecimiento de la Agenda. Se consideraron diez categorías para el análisis del contenido de las noticias y su ponderación en la estimación del índice. El índice de mediatización fue considerado bajo a partir del cual se dedujo que el sesgo informativo de la prensa no influiría en la opinión pública. Sin embargo, al enfocarse la mediatización de los periódicos en la categoría peligro esta permitió abrir la discusión en torno a las dimensiones y niveles de análisis de las categorías.

Palabras claves -Ciclos, Inseguridad, Migración, Mediatización, Contextualización, Enmarcado e Intensificación.

\footnotetext{
${ }^{1}$ UAT, Tlaxcala: artuross@uat.mx

2 UACM, CDMX: fermin.anguiano@uacm.edu.mx

3 UAEH, Tepeji: hmolina@uaeh.edu.mx

${ }^{4}$ USON, Navojoa: Izallas@navojoa.uson.mx

${ }^{5}$ UAEMEX, Huehuetoca: wialdanab@uaemex.mx

${ }^{6}$ UAM, CDMX: gperezc@correo.xoc.uam.mx

${ }^{7}$ UNAM; Nezahualcóyotl: bundesnanza@outlook.com

${ }^{8}$ CEPS, Cuernavaca: garcialirios@aol.com
} 
Año 11.

Núm. 28
Revista de Investigación Académica sin Frontera ISSN: 2007-8870

\title{
http://revistainvestigacionacademicasinfrontera.com
}

\begin{abstract}
The objective of this study is to establish a socio-psychological cycle of insecurity related to migration and its corresponding index to measure the degree of mediatization of the press around the journalistic notes on the problem. For this purpose, the theory of cycles and the Theory of the Establishment of the Agenda were used. Ten categories were considered for the analysis of news content and its weight in the estimation of the index. The mediatization index was considered low, from which it was deduced that the news bias in the press would not influence public opinion. However, by focusing on the mediatization of newspapers in the danger category, this allowed opening the discussion about the dimensions and levels of analysis of the categories.
\end{abstract}

Keywords -Cycles, Insecurity, Migration, Mediatization, Contextualization, Framing and Intensification.

\section{Introducción}

El análisis de la inseguridad puede realizarse a partir de sus efectos migratorios. Los estudios psicosociológicos de la inseguridad la han definido como un ciclo descendente de agresión, injuria, injusticia, ansiedad, peligro, desesperación, pánico, depresión, venganza y discriminación. Al ser la inseguridad un indicador negativo de los ciclos económicos, políticos y sociales incrementa los flujos migratorios globales y locales. Al estar en medio de la descapitalización, la ingobernabilidad y el desempleo, la inseguridad modera el impacto de estos factores sobre los flujos migratorios (Carreón, Blanes y García, 2018).

La inseguridad es parte de los ciclos económicos, políticos y sociales. A partir de estadísticas de inversión, legislaciones y movilizaciones, Cuatro ciclos consecutivos de 55, 45, 50 y 64 años en el que se aprecian ascensos; prosperidad económica, legitimidad política y pleno empleo, posteriores descensos; descapitalización, ingobernabilidad y desempleo (Aldana, Rosas y García, 2018).

A partir de los ciclos, es posible ubicar los eventos socioeconómicos y sociopolíticos en el ascenso o descenso de la curva cíclica. Los acontecimientos que han impactado la historia de 
Año 11.

Núm. 28
Revista de Investigación Académica sin Frontera ISSN: 2007-8870

\section{http://revistainvestigacionacademicasinfrontera.com}

la humanidad. En torno a la inseguridad, los ciclos la consideran como una fase cíclica descendiente (Carreón, García y Blanes, 2018).

En este sentido, la inseguridad, desde la óptica de los ciclos, es una consecuencia de la descapitalización, la ingobernabilidad y el desempleo. Asociada con la violencia, la inseguridad inicia con un evento considerado agresivo en el cual se desatará un conflicto de intereses (Martínez, Anguiano y García, 2018).

Los ciclos económicos, políticos y sociales parecen reactivarse a partir de conflictos en los que el indicador principal es la inseguridad. En esta fase del ciclo, inseguridad y conflicto son sinónimos. En tanto que el conflicto devela las relaciones asimétricas, unos se observan superiores a otros que se ven a sí mismos como agraviados, la inseguridad avizora consecuencias ascendentes que podrían terminar en la reconciliación o en violencia entre las partes (García, Carreón y Hernández, 2018).

La reconciliación es un acuerdo entre las partes dispuestas a establecer relaciones simétricas, unos se ven como iguales a otros que exigían justicia. La violencia refiere a la construcción de enemigos justificada por la magnitud de agravios entre las partes (Mendoza, Carreón, Mejía y García, 2018).

No obstante, la inseguridad alude tanto al ascenso (reconciliación) como al descenso (violencia). Puesto que la inseguridad es una fase cíclica, la comunicación entre las partes es la estrategia principal para superar el conflicto de intereses. Una vez identificadas y salvadas las barreras para la comunicación, la inseguridad es sustituida negociados entre las partes que iniciaran pactos, acuerdos y tratados de no agresión (García, Carreón y Hernández, 2018).

Sin embargo, los conflictos socioeconómicos y sociopolíticos tales como el desempleo y el narcotráfico parecen denostar la comunicación, negociación y acuerdos entre las partes. Cuando éstos se agudizan, la migración definida como la redistribución de exiliados en zonas 
Año 11.

Núm. 28
Revista de Investigación Académica sin Frontera ISSN: 2007-8870

\section{http://revistainvestigacionacademicasinfrontera.com}

de inversión, gobernabilidad y empleo lejanos a la felicidad, pero cercanas a estabilidad, subyace como una alternativa de solución ante las crisis económico-políticas y sociales de las zonas de exilio (Quintero, Hernández, Sánchez, Molina y García, 2017).

Los flujos migratorios globales de los países ubicados en el descenso de sus ciclos económicos, políticos y sociales a los países con ciclos prósperos. Puede observarse que la migración, en América Latina, tiene como principal causa las crisis económicas conocidas como descapitalización y las crisis políticas conocidas como ingobernabilidad. Ambas contribuyen al surgimiento de flujos migratorios incentivados por la inseguridad en los países expulsores e incentivados por la flexibilización del empleo en los países receptores (Carreón, Hernández y García, 2017).

En el caso de México, los flujos migratorios tienen su origen en zonas demográficas urbanas del 40 al 50 por ciento, lo cual indica que las sequías y la inseguridad están expulsando a los campesinos a otras regiones del país y los Estados Unidos de América (USA por sus siglas en inglés). No obstante, la migración interna parece redistribuir a la población en zonas urbano-turísticas como son los casos de Baja California Sur y Quintana Roo. La densidad poblacional y la disponibilidad de los recursos naturales, principalmente hídricos en las zonas urbano-turísticas, no incide en la expulsión, sino en la recepción de migrantes (García, Sandoval y Aguilar, 2016).

Los municipios en donde la violencia parece no tener un ciclo descendente hacia la reconciliación. Por el contrario, el ciclo de violencia parece dirigirse hacia un círculo vicioso de agresión más que de reconciliación y prevención del delito. Si se observan los conglomerados municipales más violentos y se comparan con las áreas de influencia de los cárteles, es posible observar que los conflictos por el mercado de consumo entre los cárteles del narcotráfico parecen incidir en la espiral de violencia sin visos de cambio hacia la reconciliación y la prevención del delito (García, Carreón y Hernández, 2016). 
Año 11.

Núm. 28
Revista de Investigación Académica sin Frontera ISSN: 2007-8870

\section{http://revistainvestigacionacademicasinfrontera.com}

No obstante que la inseguridad es una fase de los ciclos económicos, políticos y sociales, en el caso de México, el proceso de violencia parece incrementarse y no tener fin. Incluso, representa una amenaza para la seguridad nacional de Estados Unidos y América Latina (Mejía, Carreón y García, 2016).

Los estudios comunicológicos de la mediatización se han configurado en tres tradiciones a partir de los efectos, la recepción y la socialización de los medios masivos de comunicación. La diversidad de teorías, métodos y técnicas de investigación permite la construcción de modelos integrales en los que se complementarían los conceptos tales como; los contextos (settings), encuadres (framings), intensidades y direcciones (primings) de los mensajes. Es decir, los medios de comunicación influyen sobre la opinión pública a través de la mediatización (García, Carreón y Hernández, 2016).

Los medios tienden a difundir más imágenes que conceptos. Se trata de procesos periféricos de recepción, aceptación, decisión y consumo afectivos más que procesos centrales racionales. Una representación racional del entorno y de sí mismo sería el antecedente de la persuasión. Si el impacto de la información sobre los estilos de vida es indirecto, la mediatización regula el impacto de los hechos sobre la identidad. Al tergiversar los eventos, manipular las situaciones o fragmentar los hechos, los medios de comunicación moderan el impacto de los hechos sobre las decisiones públicas y privadas. Se trata de la mediación social que emerge ante las asimetrías de intereses como factor de cambio intercultural (García, 2015).

En América Latina, la mediatización se estudia desde tres orientaciones; la europea histórica filosófica, la norteamericana positivista sistémica y la europea semiótica estructuralista. Tres dimensiones derivan de estas orientaciones. 
Año 11.

Núm. 28
Revista de Investigación Académica sin Frontera ISSN: 2007-8870

\section{http://revistainvestigacionacademicasinfrontera.com}

- Producción y distribución del mensaje.

- Análisis del contenido de la información.

- Recepción y apropiación comunicativa.

- Uso social mediático

○ Industrialización cultural

○ Recepción activa

○ Identidades complejas

○ Sistemas multimediacionales

A partir de los estudios referidos, la mediatización puede ser definida como la industrialización, producción, difusión, recepción e identidad en torno a mensajes sobre sustentabilidad para la formación de opinión pública que minimiza o maximiza la interdependencia entre las situaciones de los recursos y los estilos de vida.

La Teoría del Establecimiento de la Agenda (TEA) asegura que los medios de comunicación difunden temas de violencia a partir de sus intereses y no de la tendencia de casos del fuero común o federal. Dicha prevalencia, tiene un efecto sobre la percepción de inseguridad de las audiencias y en el caso de los medios impresos, el efecto es el discurso de sus lectores sobre la violencia y particularmente, los homicidios dolosos (García, Carreón, Hernández, Aguilar, Rosas, Morales y García, 2015).

Los postulados de la Teoría del Establecimiento de la Agenda permiten explicar el proceso de construcción de la agenda mediática, pública y sobre todo política en torno a la inseguridad, la violencia, los homicidios, los perfiles y la impunidad (Rivera, García, García, Rosas, Carreón, Hernández y Morales, 2015).

Los estudios mediáticos han demostrado la selección, fragmentación y sesgo del ejercicio periodístico con estudios de sondeo simultáneo en el que las percepciones de los encuestados 
Año 11.

Núm. 28
Revista de Investigación Académica sin Frontera ISSN: 2007-8870

\section{http://revistainvestigacionacademicasinfrontera.com}

son una extensión de la agenda de los medios. Por otra parte, los experimentos de recepción y percepción corroboran no sólo el sesgo informático, sino además su poder de influir en la opinión pública (Carreón y García, 2014).

No obstante, la TEA refiere solamente al sesgo informativo sin precisar un tiempo y espacio definidos para su comprobación empírica. En efecto, la tendencia ha sido medir simultáneamente, durante un lapso determinado, el sesgo mediático y la influencia en la percepción de la gente (Mejía y García, 2015).

Sin embargo, no es posible, realizar dos diagnósticos simultáneos de los hechos y concluir que existe una relación directa y significativa entre ellos. Si partimos de la premisa en torno a la cual un hecho es observable simultáneamente más de una vez, entonces tendríamos que pensar que la percepción si y sólo si está influida por los medios olvidando que puede estar influida por el hecho en sí, por otros acontecimientos relacionados, por experiencias directas, indirectas e incluso por otras notas informativas.

El sesgo informativo es inherente al ejercicio periodístico y esto significa que en realidad los medios no influyen directamente en la agenda-setting pública. Es decir, los medios son sólo intermediarios de los errores del ejercicio periodístico.

No obstante, el planteamiento en torno al establecimiento de la agenda-setting, así como sus fases no son inductivas ya que sólo se consideran las noticias externas susceptibles de ser codificadas para demostrar la incidencia de los medios de comunicación en la opinión pública (Carreón, Hernández, Morales, Bustos y García, 2014).

La Teoría del Establecimiento de la Agenda estaría cercana al análisis de las noticias internacionales que la opinión pública no puede conocer directamente y por ello se ve sumamente influenciada por los medios de comunicación dado que otras fuentes de información, incluso internet, no ofrecen contenidos cercanos al entendimiento de las 
Año 11.

Núm. 28
Revista de Investigación Académica sin Frontera ISSN: 2007-8870

\section{http://revistainvestigacionacademicasinfrontera.com}

personas comunes y corrientes que aprenden con base en imágenes más que con base en discursos estructurados o razonamientos lógicos científicos.

Al construir una agenda mediática, los medios de comunicación construyen una agenda pública y política esencial para el Estado. Es decir, los medios de comunicación utilizan marcos de referencia en los que la opinión pública se basa para construir su agenda de discusión pública. Se trata de atributos en torno a un tema que orientan la percepción, selección y recepción de la información por parte de las audiencias. El establecimiento de la agenda es un efecto de resonancia informativa en el que los medios emiten temas que a posteriori las audiencias amplificarán o disminuirán su relevancia, pero en definitiva incluirán en su agenda de discusión una vez que los medios se han encargado de difundir la noticia (Hernández, Carreón, García, Bustos, Morales y Rivera, 2014).

En este sentido, la agenda es una colección de temas compartidos por comunicadores, políticos y audiencias. No obstante, los estudios sobre el establecimiento de la agenda se enfocan en el proceso por el cual los medios de comunicación seleccionan los temas que las audiencias decepcionarán como de suma importancia y posteriormente discutirán con base en los conceptos difundidos por los medios.

Los medios de comunicación invisten de atributos los temas para facilitar su inclusión en la agenda pública. A través de los titulares y encabezados, los medios masivos de comunicación difunden expectativas en sus audiencias. Esto corrobora la hipótesis en torno a la cual los medios de comunicación influyen en la sociedad produciendo temas y colocándolos en la agenda de discusión pública. Los medios de comunicación masiva determinan y dictan los temas que la gente comentará. La opinión pública construirá percepciones sobre la importancia de los temas expuestos en los medios. Posteriormente, la gente comentará los temas incluso con las palabras utilizados por los profesionales de la comunicación en 
Año 11.

Núm. 28
Revista de Investigación Académica sin Frontera ISSN: 2007-8870

\section{http://revistainvestigacionacademicasinfrontera.com}

televisión, radio, prensa e internet (García, Carreón, Hernández, Aguilar, Rosas, García y Mejía, 2015).

La relación entre el establecimiento de la agenda con la formación de actitudes y decisiones de discusión en torno a los temas seleccionados por los medios y aceptados por la opinión pública como los asuntos públicos de mayor interés e importancia. Se trata de un efecto mediático que construye la opinión pública a través de sus expectativas e intenciones de llevar a cabo una discusión pública al interior del grupo de referencia o pertenencia. El establecimiento de la agenda pública se construye con estrategias de contexto tales como; mayor primacía, cobertura, tiempo y espacio a noticias relativas. En esto consistiría el poder mediático ya que los medios de comunicación pueden enfatizar un tema sin tener que asumir riesgos (Carreón y García, 2013).

El énfasis político en los temas que permitieron corroborar la hipótesis del establecimiento de la agenda. Reducen a las audiencias a meros espectadores incapaces de seleccionar información y construir su agenda de discusión. Paradójicamente, la investigación se orientó hacia los efectos psicológicos de los medios de comunicación en la opinión pública. Finalmente, la agenda es un problema social, a menudo conflictivo, que ha recibido cobertura mediática sesgando la atención del público hacia determinados objetos o cuestiones de la escena política y social en los que el público confía y asigna importancia en función del grado de relevancia mediático (García, Carreón, Hernández, Mejía, García y Rosas, 2014).

\section{Método}

Se realizó un estudio exploratorio, retrospectivo y transversal en el que se analizaron las noticias relativas la inseguridad que experimentan los migrantes en su trayectoria y que ha sido reportada por la prensa nacional. 
Año 11.

Núm. 28
Revista de Investigación Académica sin Frontera ISSN: 2007-8870

\section{http://revistainvestigacionacademicasinfrontera.com}

Se seleccionaron 111 noticias de periódicos de circulación nacional. Se consideraron sólo aquellas notas informativas que documentaban extractos de entrevistas relativas a migrantes afectados por la inseguridad.

Categorías. La elaboración del presente estudio considero las fases de la inseguridad; agresión, injuria, injusticia, ansiedad, peligro, desesperación, pánico, depresión, venganza y discriminación.

- La agresión fue definida como un acto deliberado, alevoso y ventajoso de una persona o grupo expuesto en la prensa como delincuente hacia una persona o grupo migrante considerado como víctima.

- La injuria es un delito incentivado por alguna de las partes en conflicto de intereses y expuesta por la prensa como acusaciones directas e indirectas de una persona o grupo hacia otro individuo o grupo.

- La injusticia alude a las percepciones sesgadas de enjuiciamiento y condena de los migrantes agraviados en referencia a sus ofensores y cuyos resultados no les favorecen según la opinión de periodistas.

- La ansiedad refiere a un estado emocional de bajo autocontrol en torno al cual los periodistas y reporteros atribuyen como causa psicológica de la comisión de un delito y como una consecuencia psicológica de las migrantes víctimas del delito.

- El peligro incluye percepciones y sentimientos de impotencia de los migrantes ante los hechos delictivos en torno al cual, la prensa etiqueta a un espacio, proceso, persona o grupo.

- La desesperación es mediatizada como un estado de ánimo en el que las migrantes víctimas declaran a la prensa sus emociones relativas a buscar un ser querido raptado, recuperar el patrimonio que le han hurtado o revivir a la persona asesinada. 
Año 11.

Núm. 28
Revista de Investigación Académica sin Frontera ISSN: 2007-8870

\section{http://revistainvestigacionacademicasinfrontera.com}

- El pánico alude a una emoción que la prensa califica como extrema para describir la supervivencia de las migrantes víctimas potenciales de la delincuencia.

- La depresión denota un estado emocional en el que los migrantes víctimas o potenciales víctimas acuden a refugiarse para afrontar los delitos que han padecido y aquellos que estiman sufrir en el futuro según las noticias de la prensa.

- La venganza es una emoción que la prensa identifica como un incentivo para la comisión de un delito por parte del migrante hacia raptores, homicidas, ladrones, embaucadores, estafadores o extorsionadores.

- La discriminación refiere a discursos y acciones que la prensa codifica como causas y efectos de la inseguridad en un espacio delimitado y tiempo determinado al termino de los cuales, los rotativos esperan una espiral de violencia.

Instrumentos. Se utilizaron matrices de análisis de contenido ponderativas en las que se incluye la fecha, titulo, extracto y clasificación de las noticias seleccionadas. Dicha matriz permite la suma de las ponderaciones asignadas a cada nota informativa. Una vez sumadas, se establece el Índice de Mediatización de la Inseguridad Migratoria (IMIM).

Codificación. A partir de que las noticias recaban y en muchos casos fundamentan el contexto, encuadre, intensidad y dirección de la información a partir de las declaraciones de los afectados, se asignó un valor de 0 a aquellas notas que no incluyen entrevistas, 1 a aquellas notas que incluyen declaraciones sobre inseguridad, 2 a aquellas notas que incluyen declaraciones sobre agresión, 3 a declaraciones de injuria, 4 a declaraciones de injusticia, 5 a declaraciones de ansiedad, 6 a declaraciones de peligro, 7 a declaraciones de pánico, 8 a declaraciones de depresión, 9 a declaraciones de venganza, 10 a declaraciones de discriminación. Si se trataba de una contextualización, se multiplicaba el total por 1, si se trataba de un enmarcado se multiplicaba por 2 y si se trataba de una propaganda se multiplicaba por 3. El criterio de multiplicación obedece a que la mediatización que consiste 
Año 11.

Núm. 28
Revista de Investigación Académica sin Frontera ISSN: 2007-8870

\section{http://revistainvestigacionacademicasinfrontera.com}

en contextualizar la noticia con datos tiene menor impacto que las noticias encuadradas en un aspecto socioeconómico o sociopolítico y aquellas que difunden propaganda dirigida al conflicto con miras al cambio social.

Análisis. Una vez ponderadas las noticias, fueron sumados sus codificaciones para ubicarlas en un subíndice de mediatización que se establece mediante el criterio de nula mediatización (cero puntos), muy baja mediatización (menos de 300), baja mediatización (entre 301 y 400), mediana mediatización (entre 401 y 500), alta mediatización (entre 501 y 600) muy alta mediatización (más de 600). Los criterios surgen a partir del concepto de Mediatización de la Inseguridad Migratoria en la que se sugiere un continuo de que va de la nulidad hasta la mediatización extrema. Es decir, la prensa recopila las declaraciones sobre agresión, injuria, injusticia, ansiedad, peligro, desesperación, pánico, depresión, venganza y discriminación que pueden indicar el nivel de inseguridad registrado por la prensa.

Procedimiento. Se realizó una búsqueda avanzada a través de google.com. Los criterios fueron; periódicos de circulación nacional, fecha de la noticia dentro del umbral enero de 2010 a abril de 2012, encabezado de la noticia relacionado con la inseguridad y la migración. Posteriormente, se seleccionaron las notas informativas a partir de sus contenidos contextuales, enmarcados e intensificación de sus reportajes, opiniones, entrevistas o análisis. Se vació la información en matrices de análisis (ver anexo) y se procedió a calificar en contenido de las notas seleccionadas.

\section{Resultados}

La Tabla 1 y 2 muestran las categorías de inseguridad migratoria y los niveles de análisis del contenido de las mismas. De acuerdo con los resultados, la categoría peligro obtuvo el mayor puntaje de mediatización al alcanzar la cifra de 100 puntos seguida de la categoría discriminación con 40 punto de mediatización. 
Núm. 28

ISSN: 2007-8870

\section{http://revistainvestigacionacademicasinfrontera.com}

Tabla 1. La mediatización de la Inseguridad Migratoria

\begin{tabular}{|c|c|c|c|c|c|c|c|c|c|c|}
\hline 完 & $\sum^{\infty}$ & 営 & 苞 & 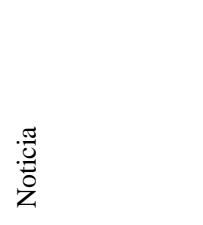 & 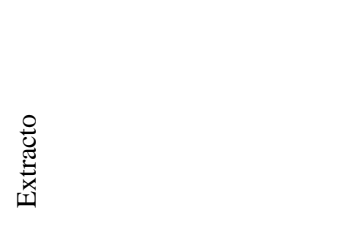 & 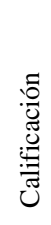 & 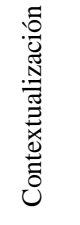 & 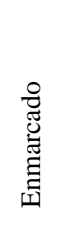 & 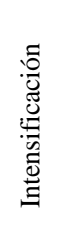 & 苟 \\
\hline 2011 & Septiembre & 6 & $\begin{array}{l}\mathrm{La} \\
\text { Jornada }\end{array}$ & $\begin{array}{l}\text { ¿Nueva } \\
\text { estrategia } \\
\text { Migratoria? }\end{array}$ & $\begin{array}{l}\text { Las muertes en la frontera } \\
\text { disminuyeron de } 234 \text { a } 168 \text { en } \\
\text { este año fiscal y eso se debe, } \\
\text { según Bersain a que han } \\
\text { enviado el mensaje de que la } \\
\text { frontera es mucho más fuerte } \\
\text { con la presencia de los agentes. }\end{array}$ & 1 & $\begin{array}{l}1 \\
(1) \\
=1\end{array}$ & $\begin{array}{l}1 \\
(0) \\
=0\end{array}$ & $\begin{array}{l}1 \\
(0) \\
=0\end{array}$ & 2 \\
\hline 2011 & Septiembre & 6 & $\begin{array}{l}\mathrm{La} \\
\text { Jornada }\end{array}$ & $\begin{array}{l}\text { ¿Nueva } \\
\text { estrategia } \\
\text { Migratoria? }\end{array}$ & $\begin{array}{l}\text { Desde la década de } 1990(\ldots) \\
\text { los indocumentados se } \\
\text { incrementaron a } 12 \text { millones, } \\
\text { de los cuales cerca de } 7 \\
\text { millones son mexicanos. } \\
\text { Había trabajo y por eso valía la } \\
\text { pena arriesgarse, pues las } \\
\text { condiciones laborales en } \\
\text { México eran lamentables. }\end{array}$ & 4 & $\begin{array}{l}4 \\
(1) \\
=4\end{array}$ & $\begin{array}{l}4 \\
(2) \\
=8\end{array}$ & $\begin{array}{l}4 \\
(3) \\
=12\end{array}$ & 28 \\
\hline 2012 & Marzo & 19 & $\begin{array}{l}\text { La } \\
\text { Jornada }\end{array}$ & $\begin{array}{l}\text { Programa piloto } \\
\text { de repatriación } \\
\text { de migrantes } \\
\text { desde Estados } \\
\text { Unidos costara } \\
50 \text { millones de } \\
\text { dólares: Instituto } \\
\text { Nacional de } \\
\text { Migración }\end{array}$ & $\begin{array}{l}\text { Se trata, explicaron ambos } \\
\text { funcionarios de romper la } \\
\text { cadena de corrupción en la } \\
\text { frontera común para evitar con } \\
\text { ello que los deportados en esa } \\
\text { zona sean víctimas de las } \\
\text { organizaciones criminales, } \\
\text { quienes "los enganchan" para } \\
\text { el trasiego de drogas, la trata y } \\
\text { la extorsión entre otros. }\end{array}$ & 5 & $\begin{array}{l}5 \\
(1) \\
=5\end{array}$ & $\begin{array}{l}5 \\
(0) \\
=0\end{array}$ & $\begin{array}{l}5 \\
(0) \\
=0\end{array}$ & 10 \\
\hline 2012 & Febrero & 29 & $\begin{array}{l}\text { La } \\
\text { Jornada }\end{array}$ & $\begin{array}{l}\text { Se piensa que la } \\
\text { migración } \\
\text { externa es causa } \\
\text { de la } \\
\text { inseguridad: } \\
\text { CONAPRED }\end{array}$ & $\begin{array}{l}80 \text { por ciento de la población } \\
\text { general opina que los derechos } \\
\text { de las personas migrantes no se } \\
\text { respetan o se respetan poco } \\
\text { (...) el desempleo, seguido de } \\
\text { la discriminación }\end{array}$ & 10 & $\begin{array}{l}10 \\
(1) \\
=10\end{array}$ & $\begin{array}{l}10 \\
(0= \\
=0\end{array}$ & $\begin{array}{l}10 \\
(0) \\
=0\end{array}$ & 20 \\
\hline
\end{tabular}


(Julio- Diciembre 2018)

Revista de Investigación

Año 11.

Académica sin Frontera

Núm. 28

ISSN: 2007-8870

\section{http://revistainvestigacionacademicasinfrontera.com}

\begin{tabular}{|c|c|c|c|c|c|c|c|c|c|c|}
\hline & & & & & 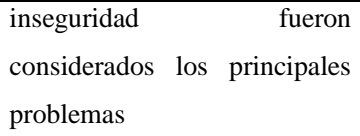 & & & & & \\
\hline 2012 & Febrero & 29 & $\begin{array}{l}\text { La } \\
\text { Jornada }\end{array}$ & $\begin{array}{l}\text { Se piensa que la } \\
\text { migración } \\
\text { externa es causa } \\
\text { de la } \\
\text { inseguridad: } \\
\text { CONAPRED }\end{array}$ & $\begin{array}{l}\text { En la población en general, } \\
\text { casi } 7 \text { de cada } 10 \text { encuestados } \\
\text { consideran que los inmigrantes } \\
\text { proporcionan divisiones y } 27 \\
\text { por ciento no aceptaría que en } \\
\text { su casa vivieran extranjeros. }\end{array}$ & 10 & $\begin{array}{l}10 \\
(1) \\
=10\end{array}$ & $\begin{array}{l}10 \\
(0= \\
=0\end{array}$ & $\begin{array}{l}10 \\
(0) \\
=0\end{array}$ & 20 \\
\hline 2012 & Febrero & 29 & $\begin{array}{l}\text { La } \\
\text { Jornada }\end{array}$ & $\begin{array}{l}\text { Se piensa que la } \\
\text { migración } \\
\text { externa es causa } \\
\text { de la } \\
\text { inseguridad: } \\
\text { CONAPRED }\end{array}$ & $\begin{array}{l}\text { Por el riesgo de que las } \\
\text { autoridades mexicanas los } \\
\text { expulsen del país y el } \\
\text { desconocimiento de sus } \\
\text { derechos, este grupo de } \\
\text { población no acude a } \\
\text { denunciar los abusos de que } \\
\text { son objetos. }\end{array}$ & 3 & $\begin{array}{l}3 \\
(0) \\
=0\end{array}$ & $\begin{array}{l}3 \\
(2) \\
=6\end{array}$ & $\begin{array}{l}3 \\
(0) \\
=0\end{array}$ & 9 \\
\hline 2012 & Febrero & 20 & $\begin{array}{l}\text { La } \\
\text { Jornada }\end{array}$ & $\begin{array}{l}\text { México no es } \\
\text { único } \\
\text { responsable de } \\
\text { maltrato a } \\
\text { migrantes del } \\
\text { sur }\end{array}$ & $\begin{array}{l}\text { En ninguna parte del mundo } \\
\text { "se da una situación en la cual } \\
\text { el migrante va caminando } \\
\text { entre algodones desde su país } \\
\text { natal hasta el de destino. No } \\
\text { hay una supercarretera donde } \\
\text { reciba trato bolsines clase", } \\
\text { asevera el subsecretario para } \\
\text { América Latina y el Caribe de } \\
\text { la Secretaria de Relaciones } \\
\text { Exteriores Rubén Alberto } \\
\text { Beltrán Guerrero, al rechazar } \\
\text { que México sea el único } \\
\text { responsable por la violación de } \\
\text { los derechos humanos de los } \\
\text { migrantes centroamericanos } \\
\text { en su trayecto hacia Estados } \\
\text { Unidos. }\end{array}$ & 5 & $\begin{array}{l}5 \\
(1) \\
=5\end{array}$ & $\begin{array}{l}5 \\
(2) \\
=10\end{array}$ & $\begin{array}{l}5 \\
(3) \\
=15\end{array}$ & 35 \\
\hline 2012 & Febrero & 20 & $\begin{array}{l}\text { La } \\
\text { Jornada }\end{array}$ & $\begin{array}{l}\text { México no es } \\
\text { único } \\
\text { responsable de } \\
\text { maltrato }\end{array}$ & $\begin{array}{l}\text { La matanza de los } 72 \\
\text { migrantes en Tamaulipas y las } \\
\text { denuncias de maltrato en el } \\
\text { trayecto hacia Estados Unidos } \\
\text { (...) pero los coyotes operan }\end{array}$ & 5 & $\begin{array}{l}5 \\
(1) \\
=5\end{array}$ & $\begin{array}{l}5 \\
(2) \\
=10\end{array}$ & $\begin{array}{l}5 \\
(3) \\
=15\end{array}$ & 35 \\
\hline
\end{tabular}


(Julio- Diciembre 2018)

Revista de Investigación

Año 11.

Académica sin Frontera

Núm. 28

ISSN: 2007-8870

\section{http://revistainvestigacionacademicasinfrontera.com}

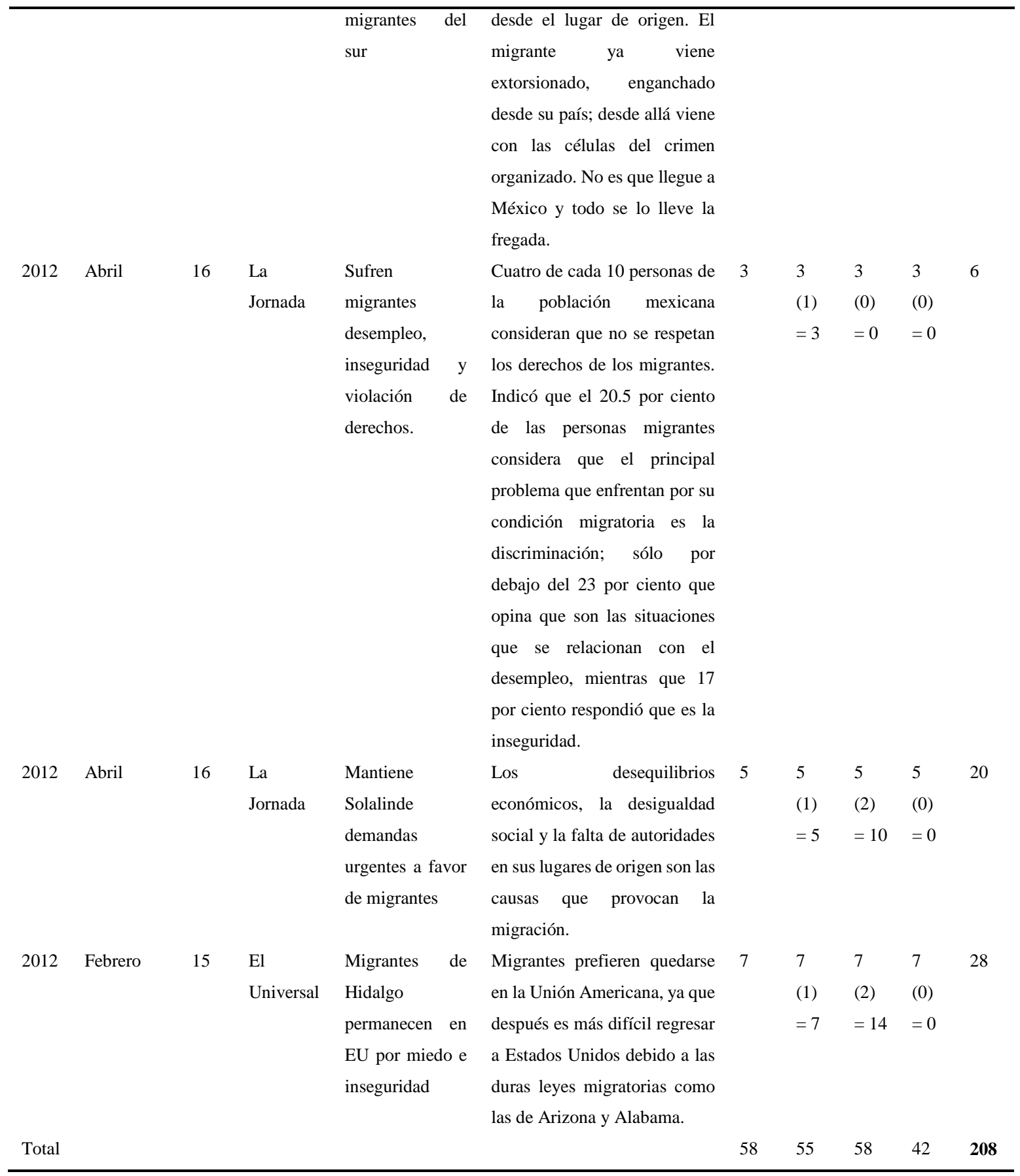

Nota: El valor de cada noticia es determinado por su nulidad $=0$, agresión $=1$, injuria $=2$, injusticia $=3$, ansiedad $=4$, peligro $=5$, desesperación $=6$, pánico $=7$, depresión $=8$, 


\section{http://revistainvestigacionacademicasinfrontera.com}

venganza $=9$ y discriminación $=10$. Cada valor es multiplicado por su contextualización $=$ 1, enmarcado $=2$ e intensificación $=3$ del extracto periodístico. Al final se suman los productos y se establece el Índice de Mediatización de la Inseguridad Migratoria

Fuente: Elaborada con los datos del estudio

Ambas categorías reflejan el significado de la inseguridad migratoria puesto que el peligro y la discriminación son dos fases permanentes de la espiral violenta hacia quienes transitan por México y se dirigen hacia los Estados Unidos de América.

Tabla 2. Índice de Mediatización de la Inseguridad Migratoria

\begin{tabular}{|c|c|c|c|c|c|c|}
\hline Inseguridad & $\begin{array}{c}\text { Valor } \\
\text { acumulado }\end{array}$ & Contextualización & Enmarcado & Intensificación & Total & Interpretación \\
\hline Nulidad & 0 & 0 & 0 & 0 & 0 & $\begin{array}{l}\text { Las noticias seleccionadas } \\
\text { incluyen mediatizaciones que no } \\
\text { pueden ubicarse en un nivel de } \\
\text { nulidad. }\end{array}$ \\
\hline Agresión & 1 & $1(1)=1$ & $1(0)=0$ & $1(0)=0$ & 1 & $\begin{array}{l}\text { La fase de agresión sólo incluyó un } \\
\text { caso contextualizado. }\end{array}$ \\
\hline Injuria & 0 & $2(0)=0$ & $2(0)=0$ & $2(0)=0$ & 0 & $\begin{array}{l}\text { Las noticias seleccionadas no } \\
\text { incluyen la injuria mediatizada en } \\
\text { sus contenidos. }\end{array}$ \\
\hline Injusticia & $3+3=6$ & $3(1)=3$ & $3(2)=6$ & $3(0)=0$ & 15 & $\begin{array}{l}\text { Dos noticias presentan contenidos } \\
\text { relativos a la injusticia }\end{array}$ \\
\hline Ansiedad & 4 & $4(1)=4$ & $4(2)=8$ & $4(3)=12$ & 28 & $\begin{array}{l}\text { Sólo un caso de las once noticias } \\
\text { incluyó a la ansiedad } \\
\text { contextualizada, enmarcada } \\
\text { intensificada. }\end{array}$ \\
\hline Peligro & $\begin{array}{c}5+5+5+5= \\
20\end{array}$ & $\begin{array}{l}5(1)+5(1)+5 \\
(1)+5(1)=20\end{array}$ & $\begin{array}{l}5(2)+5(2) \\
+5(2)=30\end{array}$ & $\begin{array}{c}5(3)+5(3)= \\
30\end{array}$ & 100 & $\begin{array}{l}\text { Cuatro casos de mediatización } \\
\text { relativa al peligro contextualizado, } \\
\text { enmarcada e intensificado. }\end{array}$ \\
\hline Desesperación & 0 & 0 & 0 & 0 & 0 & $\begin{array}{l}\text { Ningún caso de mediatización de } \\
\text { la desesperación en torno a la } \\
\text { inseguridad migratoria }\end{array}$ \\
\hline
\end{tabular}


Revista de Investigación

Año 11.

Académica sin Frontera

Núm. 28

ISSN: 2007-8870

\section{http://revistainvestigacionacademicasinfrontera.com}

\begin{tabular}{|c|c|c|c|c|c|c|}
\hline Pánico & 7 & $7(1)=7$ & $7(2)=14$ & $7(0)=0$ & 28 & $\begin{array}{l}\text { Sólo un caso relativo a la } \\
\text { mediatización del pánico } \\
\text { contextualizado y enmarcado }\end{array}$ \\
\hline Depresión & 0 & 0 & 0 & 0 & 0 & $\begin{array}{l}\text { Ningún caso de depresión } \\
\text { mediatizada en torno a la } \\
\text { inseguridad de migrantes }\end{array}$ \\
\hline Venganza & 0 & 0 & 0 & 0 & 0 & $\begin{array}{l}\text { Ningún caso de mediatización de } \\
\text { venganza relativo a la inseguridad } \\
\text { de migrantes }\end{array}$ \\
\hline Discriminación & $10+10=20$ & $\begin{array}{c}10(1)+10(1)= \\
20\end{array}$ & $10(0)=0$ & $10(0)=0$ & 40 & $\begin{array}{l}\text { Dos casos de mediatización de la } \\
\text { discriminación que sólo fueron } \\
\text { enmarcados por las notas de } \\
\text { prensa. }\end{array}$ \\
\hline Total & 58 & 55 & 58 & 42 & 213 & $\begin{array}{l}\text { Muy baja mediatización de la } \\
\text { inseguridad migratoria. Las } \\
\text { noticias relativas a la inseguridad } \\
\text { migratoria se enfocan en el peligro } \\
\text { como su contenido esencial y el } \\
\text { enmarcado como su sesgo } \\
\text { principal. }\end{array}$ \\
\hline
\end{tabular}

Nota: El valor de cada noticia es determinado por su nulidad $=0$, agresión $=1$, injuria $=2$, injusticia $=3$, ansiedad $=4$, peligro $=5$, desesperación $=6$, pánico $=7$, depresión $=8$, venganza $=9$ y discriminación $=10$. Cada valor es multiplicado por su contextualización $=$ 1 , enmarcado $=2$ e intensificación $=3$ del extracto periodístico. Al final se suman los productos y se establece el Índice de Mediatización de la Inseguridad Migratoria

Fuente: Elaborada con los datos del estudio

En contraste las categorías desesperación, depresión, venganza no son siquiera mencionadas por las notas de prensa. Llaman la atención la ausencia de mediatización de las noticias de estas categorías puesto que parecen indicar que, en México, los periódicos de circulación nacional, durante el periodo de análisis elegido, no reportan los sentimientos de desesperación, depresión y venganza de los implicados en la inseguridad migratoria, las 
Año 11.

Núm. 28
Revista de Investigación Académica sin Frontera ISSN: 2007-8870

\section{http://revistainvestigacionacademicasinfrontera.com}

opiniones y análisis de los expertos no parecen considerar éstas tres emociones y los periodistas no parecen orientar sus entrevistas a estos afectos.

Al ser la inseguridad un ciclo de emociones, sentimientos o afectos, los periódicos parecen contextualizar, enmarcar o intensificar por igual los contenidos de sus noticias.

A la luz de la Teoría del Establecimiento de la Agenda, los medios de comunicación impresos sesgan los contenidos de sus noticias sobre la inseguridad migratoria contextualizando, enmarcando e intensificando el peligro y la discriminación.

Sin embargo, una vez sumados todos los sesgos, el Índice de Mediatización de la Inseguridad Migratoria (IMIM) alcanzó los 213 puntos ubicándose en un nivel bajo de mediatización. Esto significa que la prensa sesga discretamente los contenidos de sus noticias. La baja mediatización de los periódicos La Jornada y El Universal no sería suficiente para influir en la opinión pública, la clase política, las agendas ciudadanas, política y pública.

A la luz del ciclo de la inseguridad, el IMIM parece indicar que la inseguridad migratoria se encuentra en el inicio de la fase de peligro. Este hallazgo es relevante a la luz de las políticas públicas. Dado que la mediatización indica que la inseguridad migratoria se ubica al principio de la quinta fase del ciclo, entonces será posible revertir la tendencia al reducir los riesgos con la presencia de las fuerzas públicas.

En tal sentido, la coerción de la policía y el ejército en torno al combate de la inseguridad migratoria estaría justificada al menos en términos mediáticos.

No obstante, el ciclo de la inseguridad pública es sumamente complejo. El IMIM recaba dicha complejidad al advertir que mientras en algunas fases del ciclo la prensa no reporta sucesos o hechos relacionados, en otras fases, la prensa concentra sus contextualizaciones, enmarcados e intensificaciones para influir en la opinión pública. 
Año 11.

Núm. 28
Revista de Investigación Académica sin Frontera ISSN: 2007-8870

\section{http://revistainvestigacionacademicasinfrontera.com}

Cabe señalar que el ciclo de la inseguridad y su correspondiente índice sólo explican la dimensión socio-psico-mediática y sus efectos en la opinión del individuo, principalmente sus percepciones, valores, creencias, actitudes y conocimientos. Si ambos explicaran las habilidades, intenciones y conductas de prevención o defensa contra la delincuencia a partir de su grado de información a través de la prensa, entonces los valores de ponderación se invertirían evidenciando una alta mediatización de la desesperación, la depresión y la venganza. En las categorías de análisis se incluirían la indefensión y el suicidio relacionados con la inseguridad migratoria. En consecuencia, la Teoría de la Indefensión Aprendida y la Teoría de la Depresión Suicida explicarían con mayor profundidad los procesos psicológicos como efectos de la inseguridad migratoria reportados por los medios impresos.

\section{Discusión}

El presente estudio ha establecido un ciclo y un índice en torno a la mediatización de la inseguridad migratoria para explicar el sesgo de los medios impresos en torno a la problemática.

Debido a que se utilizó la Teoría del Establecimiento de la Agenda para orientar la investigación, tanto las categorías incluidas en el ciclo como la ponderación de cada una de ellas y su posterior estimación con miras al establecimiento del índice, fueron enfocados en los procesos sociopsicológicos más que en los procesos psicológicos como efectos del sesgo informativo y la situación de inseguridad.

La diferencia entre los procesos sociopsicológico y los efectos psicológicos es sustancial.

De acuerdo con la Teoría del Establecimiento de la Agenda, los procesos sociopsicológicos son causa y efecto de la inseguridad migratoria. Tal es el caso de la discriminación, esta categoría, según la prensa, alude a la gota que derramó la espiral de la violencia en un país con desigualdad e injusticia. Es decir, el problema de inseguridad migratoria no se debe al 
Año 11.

Núm. 28
Revista de Investigación Académica sin Frontera ISSN: 2007-8870

\section{http://revistainvestigacionacademicasinfrontera.com}

maltrato, robo, extorsión, violación o asesinato que sufren los migrantes, sino se debe a que éstos no tienen manera de responder efectivamente ante estas amenazas. La prensa considera que la civilidad y la prevención del delito serían menos efectivas ante los mecanismos de justicia; denuncia, enjuiciamiento y condena de los delincuentes.

En contraste, los procesos psicológicos son considerados por la teoría como efectos y evidencias en torno a los cuales la prensa sesga la información para convertir a la inseguridad en una gota que derramó la descomposición social y la necesidad de reconstruir el tejido social a partir de la reconciliación nacional, la elección legitima del presidente, un nuevo proyecto de Estado y la inversión en educación para transformar los valores ciudadanos.

Por ello, si se ponderan psicológicamente las noticias seleccionadas para demostrar los efectos de la mediatización en torno a la inseguridad migratoria, se concluiría que la psique del individuo es la solución a la problemática reportada por los medios impresos. Al obtener las habilidades requeridas para inocular la mediatización negativa, los lectores de los periódicos seleccionarían información para tomar decisiones de prevención del delito y cuidado personal más que el cuestionamiento a los medios impresos y sus notas relativas a la inseguridad migratoria. El contenido de dicha inoculación tendría un contenido discriminatorio hacia quienes han sido mediatizados como los delincuentes que causan la inseguridad migratoria.

\section{Conclusión}

El aporte del presente trabajo al estado de la cuestión radica en el establecimiento de una agenda centrada en la seguridad pública. A partir de una selección intencional de medios impresos, se destaca una baja influencia o nivel de mediatización al comparar la frecuencia de sus notas, aunque el tipo de estudio no experimental, el tipo de selección no probabilística 


\section{http://revistainvestigacionacademicasinfrontera.com}

y el tipo de análisis de contenido limitan los hallazgos a la muestra informativa analizada; sugiriendo una extensión a otras fuentes y periodos de coyuntura electoral.

\section{Referencias}

Aldana, W., Rosas, F. J. y García, C. (2018). Especificación de un modelo para el estudio de la agenda de seguridad pública. Atlante, 9, 1-20

Carreón, J. Hernández, J. y García, C. (2017). Una revisión teórica para el estudio de la gobernanza de la seguridad pública. Epsys, 4, 1-15

Carreón, J. y García, C. (2013). Teorías de la seguridad pública y percepción del delito. Margen, 71, 1-16

Carreón, J. y García, C. (2014). Emociones y desconfianza hacia las autoridades. Virajes, 16 (1), 1-21

Carreón, J., Blanes, A. V. y García, C. (2018). Confiabilidad y validez de un modelo de gobernanza percibida de la seguridad. Sin Frontera, 11 (27), 1-43

Carreón, J., García, C. y Blanes, V. A. (2018). Redes de violencia en torno a la gobernanza de la seguridad pública. Ciencias Sociales, 4 (2), 60-65

Carreón, J., Garía, C., Vilchis, F. J., Martínez, J., Sánchez, R. y Quintana, L. D. (2016). Confiabilidad y validez de un instrumento que mide siete dimensiones de la percepción de seguridad en estudiantes de una universidad pública. Pensando Psicología, 12 (20), $65-76$

Carreón, J., Hernández, J., Morales, M. L., Bustos, J. M. y García, C. (2014). Contraste de un modelo de fiabilidad social en función de emociones relativas a la seguridad pública. Psicumex, 4 (2), 44-70

García, C. (2015). La legitimidad sociopolítica de la administración de seguridad pública en Xilitla, San Luis Potosí, México. Investigación Administrativa, 115 (44), 24-40

García, C. Carreón, J. y Hernández, J. (2016). Gobernanza del terror a la delincuencia. Eureka, 13 (2), 162-185 


\section{http://revistainvestigacionacademicasinfrontera.com}

García, C., Carreón J., Hernández, J., Mejía, S., García, E. y Rosas, F. J. (2014). Identidad sociopolítica delictiva en México. Cuadernos Hispanoamericanos de Psicología, 14 (1), 516

García, C., Carreón, J. y Hernández, J. (2017). La cogestión como dispositivo de seguridad para el desarrollo sustentable local. Eureka, 14 (2), 268-289

García, C., Carreón, J. y Hernández, J. (2018). Gobernanza de la seguridad pública. Revisión de la literatura para una discusión del estado del conocimiento de la identidad sociopolítica delictiva. Margen, 84, 1-17

García, C., Carreón, J., Hernández, J., Aguilar, J. A., Rosas, F. J., García, C. y Mejía, S. (2015). Esferas civiles de seguridad e identidad ante la corrupción establecida en la agenda de comunicación. PEI, 4 (8), 1-17

García, C., Carreón, J., Hernández, J., Aguilar, J. A., Rosas, F. J., Morales, M. L. y García, E. (2015). Confiabilidad y validez de un instrumento que mide percepciones de corrupción. Pensamiento Americano, 8 (15), 108-120

García, C., Hernández, J. y Carreón, J. (2016). Gobernanza de la seguridad pública a partir de la identidad y la percepción de riesgo establecidos de la agenda ciudadana por los medios de comunicación. Rumbos, 11 (13), 103-116

García, C., Sandoval, F. R. y Aguilar, J. A. (2016). Aproximación al encuadre de los medios en torno a 1 atención a víctimas del caso Ayotzinapa, Iguala-Guerrero (México). Seeci, 20 (39), 153-160

Hernández, J., Carreón, J., García, C., Bustos, J. M., Morales, M. L. y Rivera, B. L. (2014). Hacia la construcción de una esfera civil de seguridad e identidad pública. PEI, 4 (8), $1-12$

Martínez, E., Anguiano, F. y García, C. (2018). Governance of social work towards a network of violence. Social Science Learning Educational Journal, 3 (6), 1-3

Mejía, S. y García, C. (2015). Violencia institucional contra los migrantes centroamericanos, Trabajo Social, 1, 45-61

Mejía, S., Carreón, J. y García, C. (2016). Efectos psicológicos de la violencia e inseguridad en adultos mayores. Eureka, 13 (1), 39-55 
Año 11.

Núm. 28
Revista de Investigación Académica sin Frontera ISSN: 2007-8870

\section{http://revistainvestigacionacademicasinfrontera.com}

Mendoza, D., Carreón. J., Mejía, S. y García, C. (2018). Especificación e un modelo de representaciones propagandísticas en adultos mayores ante la seguridad pública. Tlatemoani, 25, 21-30

Quintero, M. L., Hernández, T. J., Sánchez, A., Molina, H. D. y García, C. (2017). Modelo de expectativas en torno a la seguridad púbica en microempresarios del centro de México. Sin Frontera, 10 (26), 1-20

Rivera, B. L., García, C., García, E., Rosas, F. J., Carreón, J., Hernández, J. y Morales, M. L. (2015). Contraste de un modelo de desconfianza política. Psiciencia, 7 (1), 1-9

\section{Como citar este articulo}

Arturo Sánchez Sánchez, Fermín Anguiano Salazar, Héctor Daniel Molina Ruíz, Lidia Amalia Zallas Esquer, Wilfrido Isidro Aldana Balderas, Gabriel Pérez Crisanto, Abigail Quezada Castro, Cruz García Lirios. Estructura categorial y subcategorial en la exploración de notas de prensa relativas a la administración de la seguridad migratoria. RIASF. Núm. 28, Julio-diciembre (2018), ISSN 2007-8870. pp. xx-xx. 